\title{
Immediate Bilateral Breast Reconstruction with Unilateral Deep Superior Epigastric Artery and Superficial Circumflex Iliac Artery Flaps
}

\author{
Keith S. Hansen ${ }^{1}$, Luke G. Gutwein ${ }^{2}$, Brett C. Hartman ${ }^{1}$, Rajiv Sood ${ }^{1}$, Juan Socas ${ }^{1}$ \\ ${ }^{1}$ Division of Plastic and Reconstructive Surgery, Department of Surgery, Indiana University School of Medicine, Indianapolis, IN, USA; \\ ${ }^{2}$ Department of Anatomical Sciences, Saint George's University School of Medicine, Grenada, West Indies
}

\begin{abstract}
Autologous breast reconstruction utilizing a perforator flap is an increasingly popular method for reducing donor site morbidity and implant-related complications. However, aberrant anatomy not readily visible on computed tomography angiography is a rare albeit real risk when undergoing perforator flap reconstruction. We present an operative case of a patient who successfully underwent a bilateral breast reconstruction sourced from a unilateral abdominal flap divided into deep superior epigastric artery and superficial circumflex iliac artery flap segments.
\end{abstract}

Keywords Breast / Microsurgery / Reconstructive surgical procedures
Correspondence: Luke G. Gutwein Department of Anatomical Sciences, Saint George's University School of Medicine, Grenada, West Indies Tel: +473-444-4175 Fax: $+473-4442887$ E-mail:DrGutwein@ GrenadaPlasticSurgery.com

No potential conflict of interest relevant to this article was reported.

Received: 17 Mar 2016• Revised: 28 May 2016• Accepted: 7 Jun 2016

pISSN: 2234-6163 • elSSN: 2234-6171 • http://dx.doi.org/10.5999/aps.2016.43.5.457• Arch Plast Surg 2016;43:457-460

\section{INTRODUCTION}

Bilateral breast reconstruction from abdominal perforator flaps has increased in frequency and popularity in recent decades while these flaps' advantages continue to be well documented in the literature [1]. The vascular supply to these flaps is often variable and differs in location, size, and course [2]. It was previously theorized that a history of abdominal surgeries in a patient limits the ability to utilize the transverse rectus abdominis myocutaneous and deep inferior epigastric perforator (DIEP) flaps in reconstruction. Recent reports, however, have demonstrated that abdominal wall scars including the Pfannenstiel scar are not a contraindication with appropriate planning and flap design $[3,4]$.

\section{CASE}

A 41-year-old woman with locally advanced right breast cancer presented for bilateral DIEP flap breast reconstruction (Fig. 1). She had undergone lumpectomy with positive margins followed by completion mastectomy with tissue expander placement and subsequent radiation therapy. An autologous reconstruction was desired, and her abdominal wall was considered as a source. She had undergone a total abdominal hysterectomy ten years previously, following three prior cesarean sections. Preoperative computed tomographic angiography (CTA) demonstrated several bilateral periumbilical deep inferior epigastric artery perforators of adequate size and location. Intraoperatively, we raised the right hemi-abdominal flap to find that the right superficial inferior epigastric artery and deep inferior epigastric artery (DIEA)

Copyright (C) 2016 The Korean Society of Plastic and Reconstructive Surgeons

This is an Open Access article distributed under the terms of the Creative Commons Attribution Non-Commercial License (http://creativecommons.org/

licenses/by-nc/4.0/) which permits unrestricted non-commercial use, distribution, and reproduction in any medium, provided the original work is properly cited. I www.e-aps.org 


\section{Fig. 1. Preoperative photograph}

Preoperative photograph of a 41-year-old with right breast cancer before bilateral mastectomy.

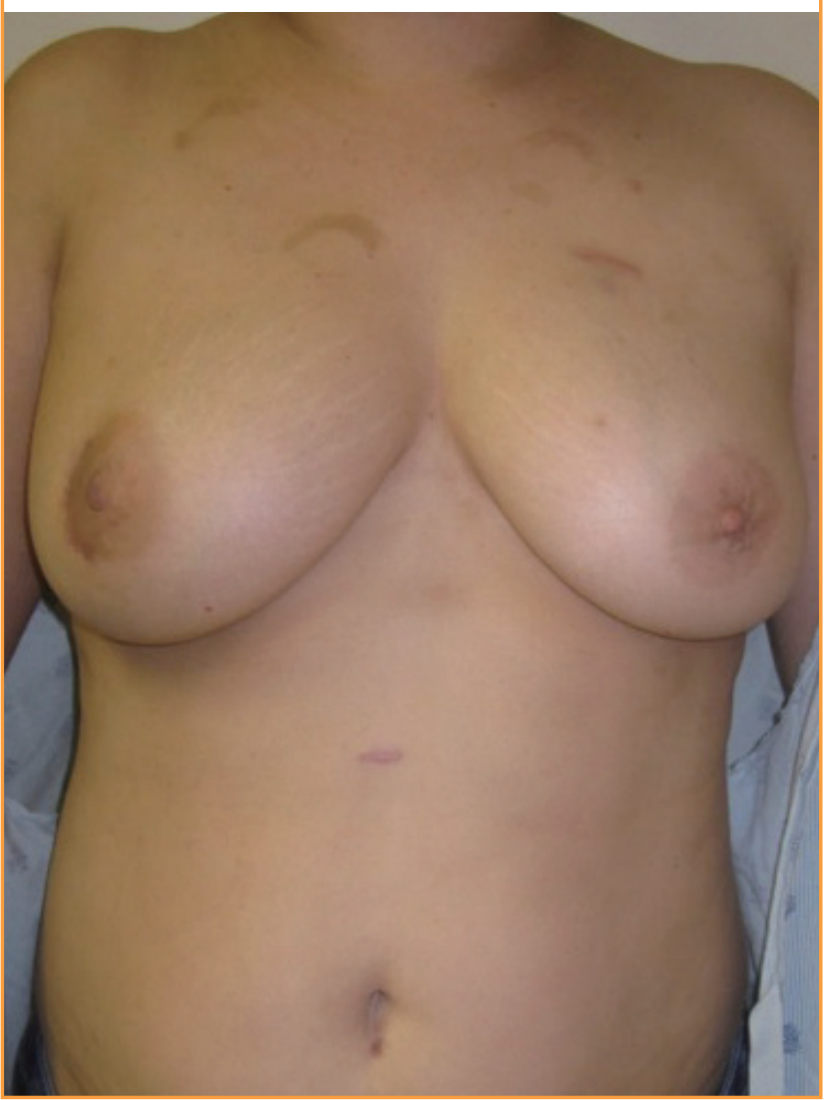

were encased in fibrotic tissue. Further dissection demonstrated the right deep superior epigastric artery (DSEA) and superficial circumflex iliac artery (SCIA) of inadequate caliber (a size mismatch of approximately $1 \mathrm{~mm}$ in diameter) for microanastomosis, leaving the right hemiflap insufficient for free tissue transfer. The left DIEA was similarly surrounded by fibrotic tissue and of insufficient caliber.

Intraoperatively, the deep inferior epigastric vessels were interrupted with scar tissue at approximately $2 \mathrm{~cm}$ from the origin of the main perforators. Fig. 2 on the preoperative CTA demonstrates the proximal left DIEA with a decrease in caliber with complete reconstitution of the vessels past this area of stenosis.

As a consequence of the aberrant anatomy, we designed two flaps for bilateral breast reconstruction from the left hemi-abdominal tissue in situ (Fig. 3) utilizing the SPY Elite perfusion assessment instrument (Novadaq Technologies, Ontario, Canada; LifeCell, Branchburg, NJ, USA). The left DSEA was initially microanastomosed to the right internal mammary artery. After successful right breast microanastomotic completion, the left hemiabdominal flap was divided (Fig. 4). Subsequently, we performed the microanastomosis of the left SCIA to the left inter-

\section{Fig. 2. Computed tomographic angiography}

Coronal section of the left proximal deep inferior epigastric artery (DIEA) (A) and axial section of the perforators (B). Computed tomographic angiography acquisition settings: 1-mm source images in the axial plane after intravenous injection of Isovue 370 on a Phillips Multidetector computed tomography, using a bolus tracking technique with the region of interest placed on the aortic arch to ensure accurate bolus timing. Post-processing was completed in three planes (axial, coronal, and sagittal) with multiplanar reconstruction and 3D maximum intensity projection during the arterial phase.
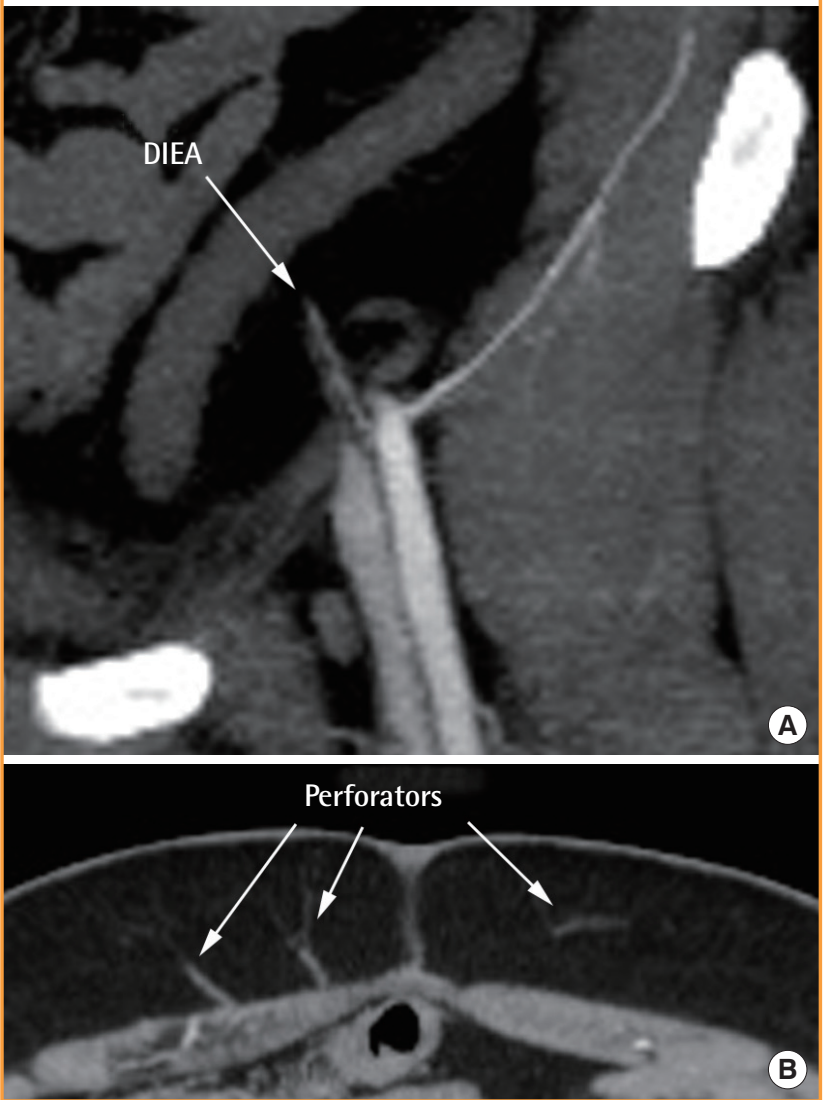

nal mammary artery followed by bilateral flap inset (Fig. 5).

Postoperatively, much less tissue volume was transferred than originally planned. We did not go directly to implant reconstruction because of the autologous tissue reconstruction desired by the patient and knowing her history of radiation therapy. The patient agreed that increased volume and improved symmetry was needed for optimizing her aesthetic outcome. Three months postoperatively, $150 \mathrm{~mL}$ and $225 \mathrm{~mL}$ high profile silicone implants were placed beneath the DSEA flap (right reconstructed breast) and SCIA flap (left reconstructed breast), respectively (Fig. 6). Implant placement was optimal for enhanced projection with excellent coverage beneath the perforator flaps. Implant placement beneath DIEP flap breast reconstruction has been previously described [5] and helps achieve symmetry while offering superior tissue coverage over an implant in a radiated field. 


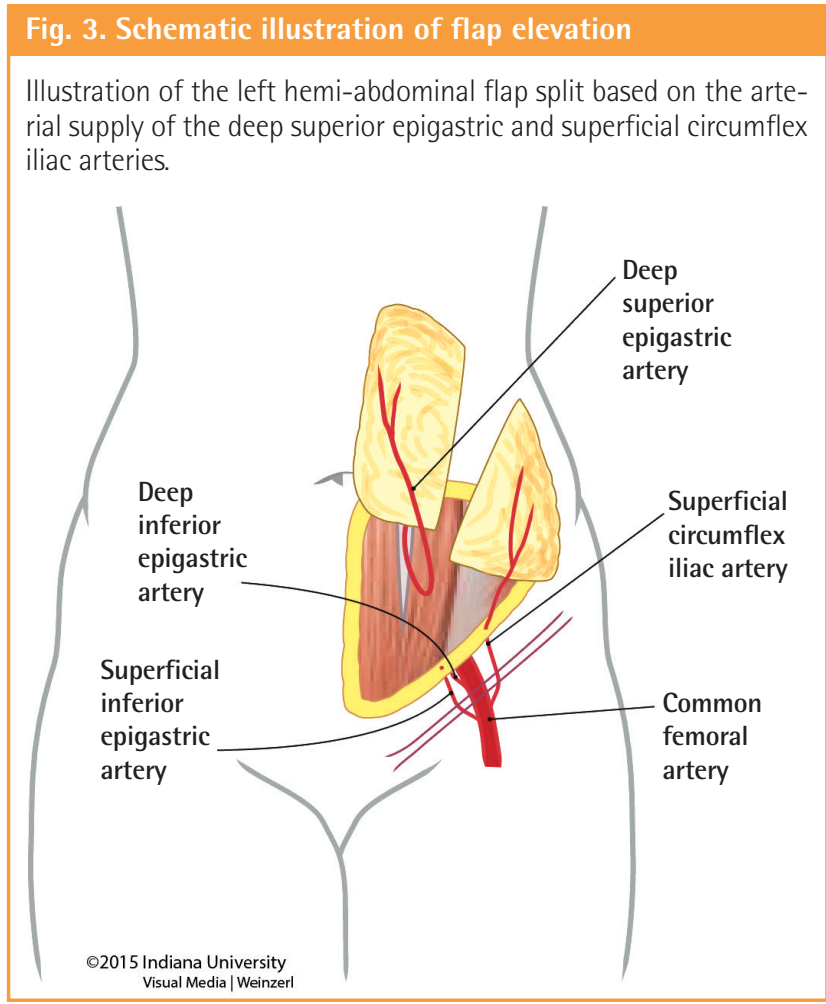

Fig. 4. Intraoperative photograph

Intraoperative photograph showing the planned division of the left hemi-abdominal flap after microanastomosis of the left deep superior epigastric artery to the right internal mammary artery.

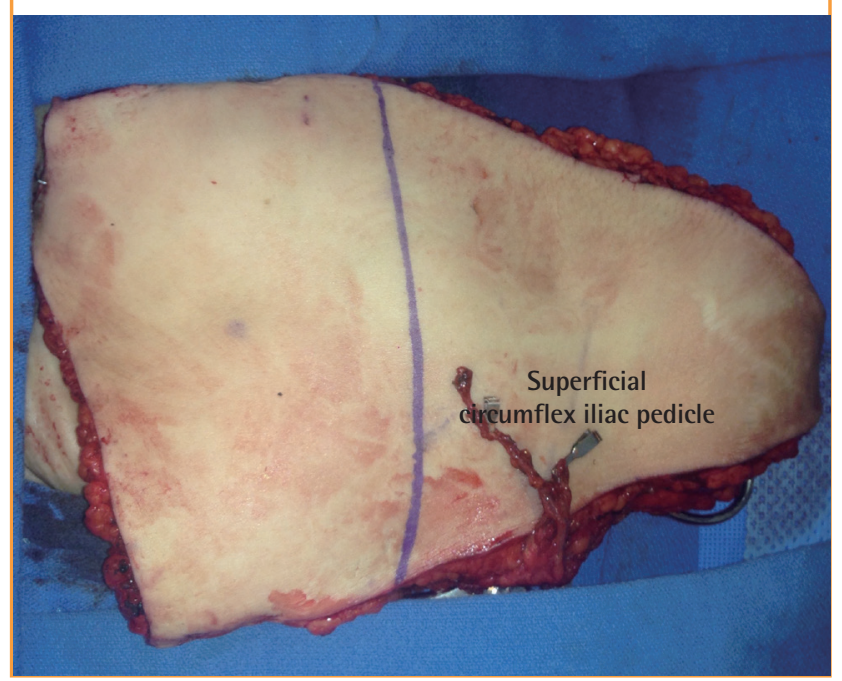

\section{DISCUSSION}

CTA has emerged as a key preoperative tool in surgical planning of perforator flaps, allowing for the precise identification of dominant perforators while reducing operating time and complications [6]. The anatomic accuracy of abdominal wall CTA has been found to have a sensitivity of $96 \%-100 \%$ and specificity of

\section{Fig. 5. Intraoperative photograph}

Intraoperative photograph of the completed inset of the deep inferior epigastric artery (right breast reconstruction) and superficial circumflex iliac artery (left breast reconstruction) flaps.

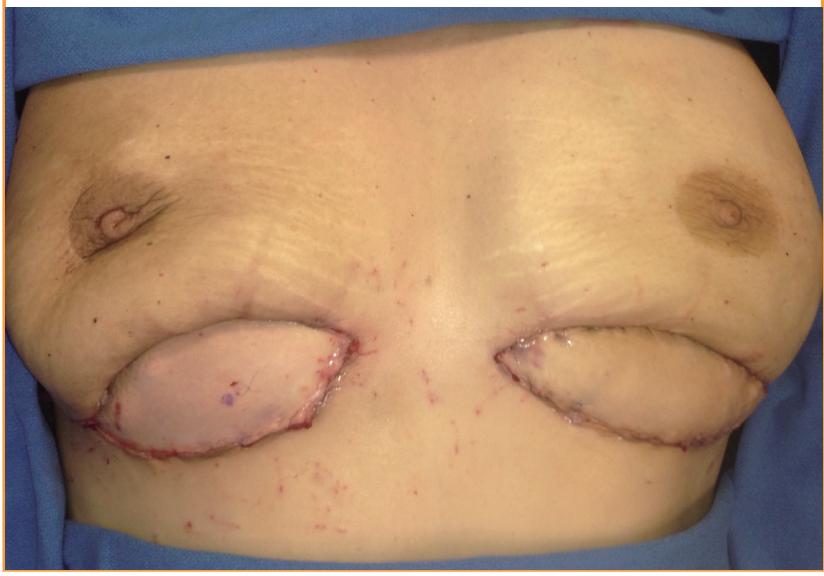

\section{Fig. 6. Three months postoperative photograph}

Outcome after placement of high profile silicone implants beneath the autologous perforator flap breast reconstruction.

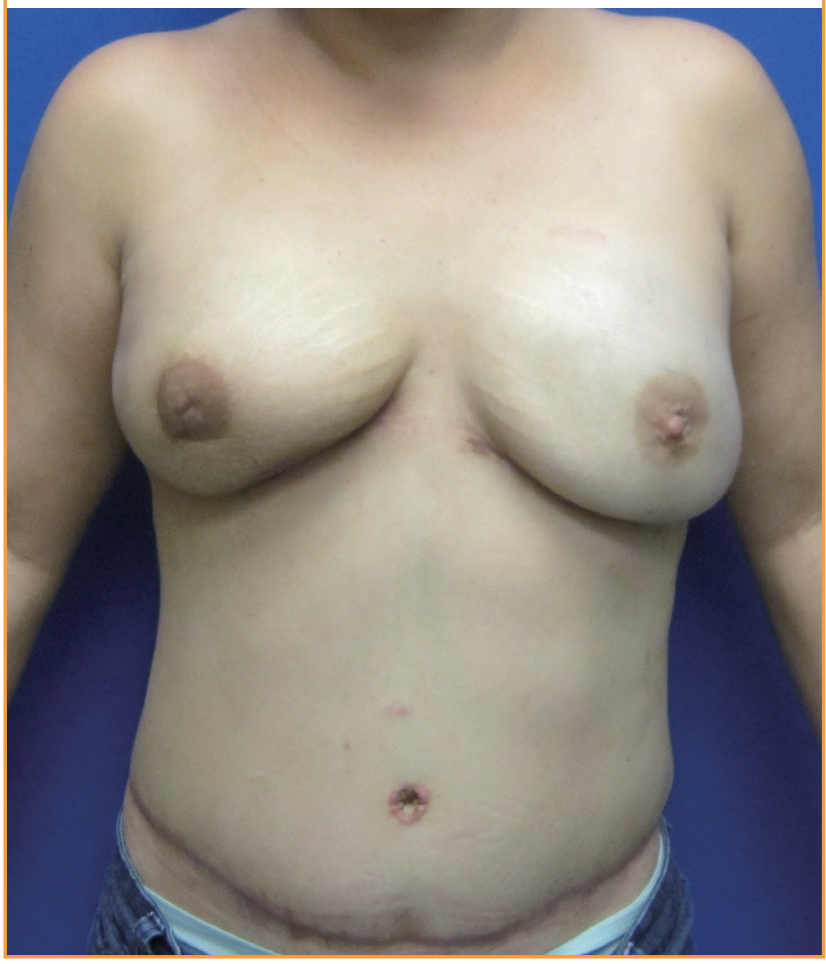

95\%-100\% in clinical and cadaveric studies [7-9]. Recent studies have further shown the superiority of CTA compared with Doppler and duplex ultrasounds $[10,11]$. While these studies have proven the accuracy of CTA in determining perforator position, information about the caliber and adequacy of a perforator remains lacking. Intraoperative inspection of planned perforators has often found them to be less robust than on imaging 
and insufficient for transfer. In evaluating the clinical utility of CTA in DIEP free flaps, Keys et al. [12] noted the importance of surgical judgment in selecting perforators and cautioned against over-reliance on imaging. In their study 23 of 52 flaps (44\%) underwent intraoperative changes due to features not noted on preoperative computed tomography. However, Rozen et al. [8], in a cadaveric study of 154 perforators in 10 hemiabdominal walls, revealed a sensitivity of $96 \%$ and positive predictive value of $95 \%$ when comparing CTA and surgical dissection measurements of perforators from an umbilical reference point. While CTA continues to serve as the gold standard in preoperative planning for perforator flaps, it is important for surgeons to rely foremost on their clinical judgment and use imaging as a supplement.

In the case presented, intraoperative surgical judgment transcended preoperative planning of the CTA. This case emphasizes the importance of a versatile reconstructive plan as well as clinical resilience in real-time. Although adequately sized muscular perforators were present, fibrotic tissue consequent of prior operations encased the DIEA bilaterally. These findings were not appreciated or adequately illustrated preoperatively on the CTA. Thus, this case illustrates the importance of an adaptable surgical plan based on individual aberrant anatomy.

\section{REFERENCES}

1. Hallock GG. If based on citation volume, perforator flaps have landed mainstream. Plast Reconstr Surg 2012;130:769e$771 \mathrm{e}$.

2. Rozen WM, Murray AC, Ashton MW, et al. The cutaneous course of deep inferior epigastric perforators: implications for flap thinning.J Plast Reconstr Aesthet Surg 2009;62:98690.

3. Rozen WM, Whitaker IS, Ting JW, et al. Deep inferior epigastric artery perforator flap harvest after abdominoplasty with the use of computed tomographic angiography. Plast Reconstr Surg 2012;129:198e-200e.

4. Park YJ, Kim EK, Yun JY, et al. The influence of pfannenstiel incision scarring on deep inferior epigastric perforator. Arch Plast Surg 2014;41:542-7.

5. Figus A, Canu V, Iwuagwu FC, et al. DIEP flap with implant: a further option in optimising breast reconstruction. J Plast Reconstr Aesthet Surg 2009;62:1118-26.

6. Teunis T, Heerma van Voss MR, Kon M, et al. CT-angiography prior to DIEP flap breast reconstruction: a systematic review and meta-analysis. Microsurgery 2013;33: 496-502.

7. Cina A, Barone-Adesi L, Rinaldi P, et al. Planning deep inferior epigastric perforator flaps for breast reconstruction: a comparison between multidetector computed tomography and magnetic resonance angiography. Eur Radiol 2013;23: 2333-43.

8. Rozen WM, Ashton MW, Stella DL, et al. The accuracy of computed tomographic angiography for mapping the perforators of the DIEA: a cadaveric study. Plast Reconstr Surg 2008;122:363-9.

9. Masia J, Clavero JA, Larranaga JR, et al. Multidetector-row computed tomography in the planning of abdominal perforator flaps. J Plast Reconstr Aesthet Surg 2006;59:594-9.

10. Scott JR, Liu D, Said H, et al. Computed tomographic angiography in planning abdomen-based microsurgical breast reconstruction: a comparison with color duplex ultrasound. Plast Reconstr Surg 2010;125:446-53.

11. Rozen WM, Phillips TJ, Ashton MW, et al. Preoperative imaging for DIEA perforator flaps: a comparative study of computed tomographic angiography and doppler ultrasound. Plast Reconstr Surg 2008; 121 (1 Suppl):1-8.

12. Keys KA, Louie O, Said HK, et al. Clinical utility of CT angiography in DIEP breast reconstruction. J Plast Reconstr Aesthet Surg 2013;66:e61-5. 